\title{
Enhancing Tumor Cell Response to Multidrug Resistance with pH-Sensitive Quercetin and Doxorubicin Conjugated Multifunctional Nanoparticles
}

\author{
Cenk Daglioglu* \\ Department of Molecular Biology and Genetics, Faculty of Science, Izmir Institute of Technology, Urla/Izmir 35430, Turkey
}

\section{A R T I C L E I N F O}

\section{Article history:}

Received 20 February 2017

Received in revised form 28 April 2017

Accepted 6 May 2017

Available online 10 May 2017

\section{Keywords:}

Multifunctional nanoparticles

Bioconjugation

Multidrug resistance

Combination cancer therapy

Drug delivery

\begin{abstract}
A B S T R A C T
Classical chemotherapy uses chemotherapeutic agents as a mainstay of anticancer treatment. However, the development of multidrug resistance to chemotherapy limits the effectiveness of current cancer treatment. Nanosized bioconjugates combining a chemotherapeutic agent with a pharmacological approach may improve the curative effect of chemotherapeutic agents. Herein I addressed this issue by describing the synthesis, and testing of, pH-responsive Fe304@SiO2(FITC)-BTN/QUR/DOX multifunctional nanoparticles. The particles were designed to modulate resistance-mediating factors and to potentiate the efficacy of DOX against chemoresistance. The physicochemical properties of the nanoparticles were characterized based on the combination of several techniques: dynamic light scattering (DLS), zeta-potential measurement, Fourier transform infrared spectroscopy (FTIR), electron microscopy techniques (SEM and STEM with EDX) and an in vitro pH-dependent release study. Cellular uptake and cytotoxicity experiments demonstrated enhanced intracellular delivery and retention of nanoparticles in the cytoplasm and efficient reduction of cancer cell viability in drug-resistant lung carcinoma A549/DOX cell lines. This did not affect internalization and viability of an immortalized human lung epithelial cell line BEAS-2B. Moreover, proapoptotic and antiproliferative studies showed that Fe304@SiO2(FITC)-BTN/QUR/DOX nanoparticles can promote apoptosis, inhibit tumor cell proliferation, and enhance the chemotherapeutic effects of DOX against multidrug resistance. These results confirm that this multifunctional platform possesses significant synergy between QUR and DOX and is promising for development as an antitumor treatment in cancer therapy.
\end{abstract}

(c) 2017 Elsevier B.V. All rights reserved.

\section{Introduction}

Multidrug resistance (MDR) to chemotherapeutic agents is one of the major unsolved problems for the success of cancer chemotherapy [1]. A number of different mechanisms, either inherent or acquired, can mediate the development of MDR against every effective anticancer drug. These mechanisms include decreased drug uptake, increased drug efflux, activation of detoxifying systems, superior DNA repair mechanisms and defective apoptotic pathways [2]. The etiology of MDR may be multifactorial, but the classic resistance that develops in cancer cells has most often been linked to the overexpression of P-glycoprotein (P-gp), an ATPdependent membrane transporter that acts as a drug efflux pump [3]. Administration of chemotherapy drugs triggers increased

\footnotetext{
* Tel.: +90 2327507319; fax: +90 2327507303.

E-mail address: cenkdaglioglu@iyte.edu.tr
}

expression of these transporters, thus effectively lowering intracellular concentrations of the chemotherapy drugs in tumor cells. To produce adequate intracellular concentrations of the chemotherapeutic, higher serum dosage is required but results in greater toxicity on normal tissues [4]. Therefore, a promising strategy to enhance the efficacy of classical chemotherapy is antagonization of resistance-mediating factors in order to restore drug sensitivity.

Modulating resistance-mediating factors as a way of reversing MDR has been extensively studied in recent years, which led to the discovery of many P-gp inhibitors for the treatment of cancers [5]. Investigations to eliminate the major limitation of the early agents in decreasing their unacceptable toxicity and unfavorable pharmacokinetic interactions prompted the development of less toxic and more potent inhibitors [6]. Although the adverse effects of these inhibitors disappeared after the introduction of third-generation agents, recent clinical trials showed disappointing results due to their toxicity and lack of pharmacological effects [7]. Therefore, investigation of natural products with potential 
MDR modulatory activity is highly anticipated. In this context, the natural flavonoid quercetin (QUR) drew much attention because epidemiological studies suggest that dietary intake of certain foods rich in flavonoids, including quercetin, have preventive activity against a broad range of cancers [8]. To date, quercetin has been reported to possess a broad spectrum MDR modulation activity. These activities are diverse and include: mimicking the adenine moiety of ATP-binding site of the ABC transporters to inhibit efflux of the drugs; accelerating TNF-alpha induced growth inhibition; inducing death receptor 5 (DR5)-mediated apoptosis; and suppressing of Akt-mediated antiapoptotic survivin expression [9-12]. Despite the multifaceted role of quercetin in reversing cancer MDR, studies that support clinical uses of flavonoid are rare, most likely because of its pharmacokinetic properties including low stability, low solubility, poor cellular uptake and fast metabolism $[13,14]$.

Previously, we have shown that bioavailability of therapeutics can be significantly improved via conjugation with a stable delivery system for the selective targeting and elimination of cancer cells. We have also confirmed that multifunctional nanoparticle-based therapeutic systems can overcome drug resistance by neutralizing various resistance mechanisms whilst simultaneously enhancing the therapeutic outcome of anticancer agents $[15,16]$. On the basis of these observations, QUR and DOX conjugated multifunctional nanoparticles were prepared herein for synergistic delivery of QUR and DOX to drug-resistant cancer cells. The new formulation of QUR could increase its potential and serve as a possible solution for its low bioactivity, thereby reducing chemoresistance while increasing the therapeutic efficacy of DOX for cancer therapy.

Considerable efforts have been devoted to improve novel multifunctional platforms toward the development of next-generation nanoparticles against drug resistance. They have been developed as an all-in-one biomedical platform with proposed configurations encompassing (1) cancer chemotherapeutics, (2) chemosensitizers, (3) molecular (diagnostic) imaging agents and (4) active targeting components [17]. Beyond these features, another important concern is the sensitivity of drug release in response to environmental stimuli at specific target sites. Therefore, the concept of stimuli-responsive nanoparticles has received much attention. Such nanoparticles are able to control drug-release after internalization, thus preventing drug leakage before reaching the tumor tissue, and improving the accumulation of chemotherapeutic agents to therapeutic levels within the target site [18].

Considering the potential importance of these multiple functions within a single platform to overcome cancer MDR, I have rationally designed the bottom-up synthesis of $\mathrm{pH}$-responsive $\mathrm{Fe}_{3} \mathrm{O}_{4} @ \mathrm{SiO}_{2}$ (FITC)-BTN/QUR/DOX nanoparticles for combination therapy comprising four major components: (1) a luminomagnetic nanocomposite as contrast agent with both magnetic $\left(\mathrm{Fe}_{3} \mathrm{O}_{4}\right)$ and optical contrast (FITC) serving as a dual imaging probe both in vivo and in vitro, (2) biotin (BTN) as a tumor specific targeting moiety to facilitate the delivery of nanoparticles to the tumor cells, (3) doxorubicin (DOX) as a model chemotherapeutic drug, and (4) quercetin (QUR) as a natural chemosensitizer aiming to modulate resistance-mediating factors. $\mathrm{Fe}_{3} \mathrm{O}_{4} @ \mathrm{SiO}_{2}$ (FITC)-BTN/QUR nanoparticles containing only chemosensitizer and $\mathrm{Fe}_{3} \mathrm{O}_{4} @ \mathrm{SiO}_{2}$ (FITC)-BTN/DOX nanoparticles containing only chemotherapeutic drug were also synthesized to evaluate the synergistic potential of different therapeutic combinations. The feasibility of nanoparticles was evaluated by investigating their capability in cellular uptake and intracellular persistence. Cytotoxicity was analyzed by comparing drug-sensitive A549 cells with drug-resistant A549/DOX cells, versus human pulmonary epithelial BEAS-2B cells. I also examined these multifunctional platforms by flow cytometric analyses of apoptosis with 7-ADD/PE-annexin-V double staining and cell cycle with propidium iodide DNA staining to evaluate their MDR- modulatory effect on the sensitivities of A549 and A549/DOX cells to DOX chemotherapy.

\section{Material and methods}

\subsection{Materials}

Iron (II) chloride tetrahydrate $\left(\mathrm{FeCl}_{2} .4 \mathrm{H}_{2} \mathrm{O}\right)$ (99\%), iron (III) chloride hexahydrate $\left(\mathrm{FeCl}_{3} .6 \mathrm{H}_{2} \mathrm{O}\right)(98 \%)$, tetraethyl orthosilicate 99.9\% (TEOS), fluorescein isothiocyanate (FITC), biotin (BTN), quercetin $\geq 98 \%$ (QUR), 3-aminopropyltriethoxysilane (APTES), N,N-dicyclohexyl-carbodiimide (DCC), N-hydroxysuccinimide (NHS), Glutaraldehyde 25\% aqueous solution, FT-IR grade potassium bromide $\geq 99 \%$ ( $\mathrm{KBr}$ ), dimethyl sulfoxide (DMSO), triton $\mathrm{X}-100, \quad 3-[4,5$-dimethyl-2-thialzolyl]-2,5-diphenyltetrazolium bromide (MTT), trypsin, RNase A and propidium iodide (PI) were purchased from Sigma-Aldrich Chemicals. Oleic acid (99\%), ammonium hydroxide $25 \%$ aqueous solution, 1-hexanol ( $>98 \%)$, cyclohexane and toluene were purchased from Fluka/Riedel-de Haën Chemicals. Doxorubicin was obtained from SABA Pharma. DMEM growth medium, 10\% Fetal bovine serum (FBS), streptomycin, penicillin and L-glutamic acid were purchased from Gibco Life Technologies. 7-aminoactinomycin (7-ADD) and PE-annexin-V were purchased from $B D$ Biosciences. All other chemicals and reagents were of the highest purity. All the experiments were performed in deionized Milli-Q water.

\subsection{Cell cultures}

A549 (human epithelial lung carcinoma) and BEAS-2B (immortalized human lung epithelial) cell lines were kindly provided by the Biotechnology and Bioengineering Research and Application Center, Izmir Institute of Technology, Turkey. A549 and BEAS-2B cells were cultured in Dulbecco's modified Eagle medium (DMEM) supplemented with $10 \%$ fetal bovine serum (FBS), $100 \mu \mathrm{g} / \mathrm{mL}$ streptomycin, $100 \mathrm{U} / \mathrm{mL}$ penicillin and $2 \mathrm{mM} \mathrm{L-glutamic}$ acid. DOX-resistant A549 cells were isolated by stepwise selection of resistant cells upon culture with increasing concentrations of DOX $(0.1 / 1 / 5 / 10 / 50 / 100 \mathrm{nM})$. Briefly, A549 cells were treated with DOX at increasing rates and when the cells were capable of growing and reaching appropriate confluency at a certain concentration, the medium was changed with the following DOX concentration for next selection of resistant cells. Finally, the A549 cells acquired DOX resistance and were cultured in medium containing $100 \mathrm{nM}$ DOX and thereafter, named as A549/DOX. The final tolerated concentration of $100 \mathrm{nM}$ DOX represents the mean plasma concentration of doxorubicin in patients under chemotherapy [19]. To eliminate the effects related to long-term culture of cancer cells, A549 and BEAS2B cells were cultured and maintained under the same conditions as the DOX-resistant A549 cells in the absence of doxorubicin. All cell lines were incubated in $5 \% \mathrm{CO}_{2}$ and $90-100 \%$ relative humidity at $37^{\circ} \mathrm{C}$.

\subsection{Synthesis of multifunctional nanoparticles}

The parental $\mathrm{Fe}_{3} \mathrm{O}_{4} @ \mathrm{SiO}_{2}$ (FITC) nanoparticles were synthesized as described in our previous work [15]. They consist of superparamagnetic iron oxide nanoparticles (as magnetic contrast agent), coated with layers of silica shells, encasing FITC within (as optical contrast agent), for imaging, biocompatibility and molecular functionalization. To ensure preferential tumor cell uptake of the nanoparticles, the outermost layer of $\mathrm{Fe}_{3} \mathrm{O}_{4} @ \mathrm{SiO}_{2}$ (FITC) was then functionalized with BTN molecules by silanization with BTNAPTES conjugate. Since biotin-specific uptake systems are highly over-expressed on the cell surface of rapidly proliferating cancer cells, biotin derivatization allows the selectively delivery of the 
nanoparticles to tumor cells in the presence of normal cells via receptor-mediated endocytosis [20]. In brief, an APTES ester of BTN (BTN-APTES) was prepared by mixing biotin $(8.0 \mathrm{mg}$ ) with APTES $(2.0 \mu \mathrm{L})$ in $40 \mathrm{~mL}$ dry dimethyl sulfoxide (DMSO) in the presence of NHS (1.1 mg) and DCC ( $4.7 \mathrm{mg})$ as the catalyst, at room temperature for $2 \mathrm{~h}$. After this, a mixture of $\mathrm{Fe}_{3} \mathrm{O}_{4} @ \mathrm{SiO}_{2}$ (FITC) nanoparticles $(100 \mathrm{mg}), \mathrm{BTN}-\mathrm{APTES}$ conjugate and free APTES $(17 \mu \mathrm{L})$ in toluene $(160 \mathrm{~mL})$ were stirred at room temperature for $24 \mathrm{~h}$ to introduce BTN-APTES conjugate and free APTES on the surface of silicacoated nanoparticles by hydrolysis and condensation of APTES through silanization. Final products were collected by a magnet, washed with toluene and ethanol several times to remove any unreacted reactants, and dried in a vacuum oven at room temperature, overnight. In this step, besides vectorization of nanoparticles, the surfaces were simultaneously modified with free APTES to form an amine-terminated overlayer for further functionalization.

$\mathrm{Fe}_{3} \mathrm{O}_{4} @ \mathrm{SiO}_{2}$ (FITC)-BTN/QUR/DOX was prepared by conjugating QUR and DOX complexes on the surface of $\mathrm{Fe}_{3} \mathrm{O}_{4} @ \mathrm{SiO}_{2}$ (FITC)$\mathrm{BTN} / \mathrm{NH}_{2}$ nanoparticles via glutaraldehyde activation. For $\mathrm{pH}-$ responsive drug release, QUR and DOX complexes were covalently linked to amine-functionalized silica surface of nanoparticles via pH-labile acetal [21] and imine [22] formation from the two hydroxyl groups on the catechol moiety of QUR and the amino sugar moiety of DOX, respectively. These acid sensitive linkages are stable at natural $\mathrm{pH}(\sim 7.4)$, but broken at mildly acidic $\mathrm{pH}(\sim 5.0)$, which allow for the release of QUR and DOX in the more acidic endosome environment ( $\mathrm{pH} 5.0)$ versus systemic circulation $\mathrm{pH}$ (7.4). Thus endow the $\mathrm{Fe}_{3} \mathrm{O}_{4} @ \mathrm{SiO}_{2}$ (FITC)BTN/QUR/DOX nanoparticles with pH-switched QUR and DOX release property. In this step, both $\mathrm{Fe}_{3} \mathrm{O}_{4} @ \mathrm{SiO}_{2}$ (FITC)-BTN/QUR and $\mathrm{Fe}_{3} \mathrm{O}_{4} @ \mathrm{SiO}_{2}$ (FITC)-BTN/DOX nanoparticles were also synthesized to evaluate synergistic potential of therapeutics. Briefly, the surface of $\mathrm{Fe}_{3} \mathrm{O}_{4} @ \mathrm{SiO}_{2}$ (FITC)-BTN/NH $\mathrm{N}_{2}$ nanoparticles (10 mg) was activated in $20 \mathrm{~mL} 1.0 \%$ glutaraldehyde solution under vigorous mechanical stirring at room temperature for $1 \mathrm{~h}$. Nanoparticles were subsequently collected via centrifugation, and the unreacted glutaraldehyde removed by extensive washing with ultrapure water. Glutaraldehyde activated nanoparticles were incubated with QUR $(100 \mu \mathrm{M})$ and/or DOX $(10 \mu \mathrm{M})$ complexes (1.0\% DMSO) in $20 \mathrm{~mL}$ PBS solution ( $\mathrm{pH} 7.4$ ) under vigorous mechanical stirring at room temperature for $6 \mathrm{~h}$. An excess amount of QUR with low-dose DOX concentration (molar ratio of QUR to DOX $=10$ ) was used to evaluate the sensitization effect of QUR and to reveal low-dose DOX effects against resistant cancer cells. The amount of bound QUR or DOX was calculated from the difference between the amount of QUR or DOX introduced into the coupling reaction mixture, and the amount of QUR or DOX present in the washing water after immobilization. This was carried out by measuring QUR and DOX absorbance at $380 \mathrm{~nm}$ and $480 \mathrm{~nm}$. The resulting nanoparticles: (1) $\mathrm{Fe}_{3} \mathrm{O}_{4} @ \mathrm{SiO}_{2}$ (FITC)-BTN/QUR; (2) $\mathrm{Fe}_{3} \mathrm{O}_{4} @ \mathrm{SiO}_{2}$ (FITC)-BTN/DOX and (3) $\mathrm{Fe}_{3} \mathrm{O}_{4} @ \mathrm{SiO}_{2}$ (FITC)-BTN/QUR/DOX were magnetically separated and washed with 1\% DMSO in PBS several times to remove any unreacted reactants and dried under vacuum at room temperature, overnight.

\subsection{Structural and physicochemical characterization}

Dynamic light scattering (DLS) measurements were performed at $25^{\circ} \mathrm{C}$, using a Malvern Zetasizer NanozS compact scattering spectrometer. Average hydrodynamic diameters, size distributions and surface charge analysis of the samples were determined using Malvern Dispersion Technology Software 7.11. Nanoparticles were suspended in ultrapure water to give optimum signal intensity. All measurements were repeated five times to verify the reproducibility of the results.
The Fourier transform infrared spectroscopy (FTIR) spectra of the nanoparticles were collected with a "PerkinElmer Spectrum100 " spectrophotometer in the range $450-4000 \mathrm{~cm}^{-1}$. The spectra of the dried samples were obtained by employing a $\mathrm{KBr}$ pellet.

Scanning electron microscopy (SEM) and energy-dispersive X-ray spectroscopy (EDX) studies were performed with a highresolution environmental scanning electron microscope (FEI Quanta 250 FEG) equipped with a Schottky field emission gun (FEG) for optimal spatial resolution and an energy-dispersive X-ray spectrometer (Oxford AZtec). Prior to examination, the lyophilized nanoparticles were placed on a double stick tape over aluminum stubs to get a uniform layer of particles.

Scanning transmission electron microscopy (STEM) images of the nanoparticles were obtained with a "FEI Quanta 250 FEG" microscope operating with STEM Detector. The nanoparticles were dispersed in water under sonication and a drop was placed on a carbon-coated 400 mesh copper grid followed by air-drying.

\subsection{In vitro release studies}

The release of drugs from the nanoparticle formulations was examined by the dialysis bag diffusion method. The aqueous suspensions of $\mathrm{Fe}_{3} \mathrm{O}_{4} @ \mathrm{SiO}_{2}$ (FITC)-BTN/QUR, $\mathrm{Fe}_{3} \mathrm{O}_{4} @ \mathrm{SiO}_{2}$ (FITC)$\mathrm{BTN} / \mathrm{DOX}$ or $\mathrm{Fe}_{3} \mathrm{O}_{4} @ \mathrm{SiO}_{2}$ (FITC)-BTN/QUR/DOX nanoparticles $(1 \mathrm{mg} / \mathrm{mL}$ ) were placed into the respective dialysis bags (MWCO $3500 \mathrm{Da}$ ) and suspended in $25 \mathrm{~mL}$ of $1 \%$ DMSO in PBS buffer solution with pH 5.0 or 7.4 at $37^{\circ} \mathrm{C}$ under gentle magnetic stirring, respectively. Then, $1 \mathrm{~mL}$ of the each release medium was withdrawn at predetermined time points and replaced with $1 \mathrm{~mL}$ of fresh buffer solution of relevant $\mathrm{pH}$. The amount of QUR and DOX in the withdrawn samples was determined using UV-vis spectrometry, at the corresponding wavelengths. All experimental procedures were repeated three times to obtain the average value. The cumulative release of QUR or DOX was calculated according to the following equation:

$$
\begin{gathered}
\text { The cumulative release of QUR or DOX }(\%)=(\text { mass of released } \\
\text { QUR or DOX/total mass of conjugated QUR or DOX }) \times 100
\end{gathered}
$$

\subsection{Cellular uptake analysis}

The cellular uptake behavior of the nanoparticle formulations was investigated in drug-sensitive A549, drug-resistant A549/DOX and non-tumoral BEAS-2B cells using fluorescence microscopy and flow cytometry. For microscopic observation, all cells $\left(1 \times 10^{5}\right.$ cells/well) were seeded in 12-well plates overnight to allow the adhesion of the cells before experiments. Next, the nanoparticle formulations were added to the incubation medium at a concentration of $10 \mu \mathrm{g} / \mathrm{mL}$ for 4 and $24 \mathrm{~h}$ of incubation to investigate time-dependent uptake and MDR-modulatory effect in $5 \% \mathrm{CO}_{2}$ at $37^{\circ} \mathrm{C}$. After incubation, all cells were washed three times with PBS and later microscopic images in the green channel, for detection of the FITC label encapsulated in nanoparticles, and in the brightfield were obtained by fluorescence microscopy. Internalization of the nanoparticles was visualized using an Olympus IX2-ILL100 fluorescence microscope equipped with an appropriate filter set. Images were acquired using a CCD camera and analyzed using ImageJ advanced version software. For cellular uptake quantitative analysis, the cells $\left(2 \times 10^{5}\right.$ cells/well) were seeded in 6 -well plates overnight before experiments. The medium from each well was discarded and cells were treated as described above. The samples were trypsinized and harvested to obtain a cell suspension, which was then analyzed for the distribution of FITC fluorescence by flow cytometry. 


\subsection{Cytotoxicity of multifunctional nanoparticles}

The cytotoxicity of the nanoparticle formulations was evaluated by MTT assay. A549, A549/DOX and BEAS-2B cells were seeded into 96 -well plates at a density of $1 \times 10^{4}$ per well and grown overnight. The cells were then incubated with increasing concentrations $(1.0 / 10 / 50 / 100 / 200 \mu \mathrm{g} / \mathrm{mL})$ of the nanoparticle formulations, free DOX $(100 \mathrm{nM})$, free QUR $(10 / 100 \mu \mathrm{M})$, and the combinations of free DOX (100 nM) and QUR $(10 / 100 \mu \mathrm{M})$, respectively, in $100 \mu \mathrm{L}$ of growth medium with $1 \%$ DMSO for $48 \mathrm{~h}$ at $37^{\circ} \mathrm{C}$ under $5 \% \mathrm{CO}_{2}$. Following this incubation, cells were incubated in medium containing $0.5 \mathrm{mg} / \mathrm{mL}$ of MTT for $4 \mathrm{~h}$. The medium was discarded, and the precipitated formazan violet crystals were dissolved in $150 \mu \mathrm{L}$ DMSO to solubilize the formazan. After shaking the plate for $10 \mathrm{~min}$, the absorbance of the sample was measured at $570 \mathrm{~nm}$ by multidetection microplate reader. The absorbance of dissolved formazan in the visible region correlates with the number of viable cells. The percentage of viable cells was calculated according to the following equation:

$$
\begin{aligned}
& \text { Cell viability }(\%)=\left(M_{\text {nanoparticles/free drugs }}-M_{\text {blank }}\right) / \\
& \left(M_{\text {control }}-M_{\text {blank }}\right) \times 100
\end{aligned}
$$

where $M_{\text {nanoparticles/freedrugs }}$ is the absorbance of the cells, growth medium and nanoparticles or free drugs, $\mathrm{M}_{\text {control }}$ is the absorbance of the cell and growth medium, and $\mathrm{M}_{\text {blank }}$ is the absorbance of the growth medium alone. Cytotoxicity was evaluated with reference to the $\mathrm{IC}_{50}$ value that was defined as the concentration of compound causing death in $50 \%$ of cells. $\mathrm{IC}_{50}$ values were calculated from dose-response curves (nanoparticle concentration vs. cell survival fraction) obtained in repeat experiments.

\subsection{Detection of apoptotic cells by flow cytometry}

The percentage of cells undergoing apoptosis induced by the nanoparticle formulations was measured using flow cytometry with 7-ADD and PE-annexin-V double staining. A549 and A549/DOX cells $\left(1 \times 10^{5}\right.$ cells/well $)$ were seeded in 6-well plates with $2 \mathrm{~mL}$ of growth medium overnight before experiments. $\mathrm{Fe}_{3} \mathrm{O}_{4} @ \mathrm{SiO}_{2}$ (FITC)-BTN/QUR, $\mathrm{Fe}_{3} \mathrm{O}_{4} @ \mathrm{SiO}_{2}$ (FITC)-BTN/DOX or $\mathrm{Fe}_{3} \mathrm{O}_{4} @ \mathrm{SiO}_{2}$ (FITC)-BTN/QUR/DOX nanoparticles were added to the incubation medium at $\mathrm{IC}_{50}$ concentrations and then the cells were incubated for $4 \mathrm{~h}$ in $5 \% \mathrm{CO}_{2}$ at $37^{\circ} \mathrm{C}$ to allow uptake of the nanoparticles. Before analysis, the cells were carefully washed with cold PBS, digested with trypsin and collected by centrifugation. The cells were washed twice with cold PBS, resuspended in $200 \mu \mathrm{L}$ of annexin binding buffer and stained with $10 \mu \mathrm{L}$ of 7-ADD and $\mathrm{PE}-\mathrm{annexin}-\mathrm{V}$. The stained cells were first incubated for $15 \mathrm{~min}$ at room temperature in the dark, and then analyzed by flow cytometry. The untreated cells incubated with medium alone were used as the controls. Unstained cells, cells stained with PE-annexin-V alone and cells stained with 7-AAD alone were used to set up compensation and quadrants. Flow cytometric analysis was performed on a FACS (Facscanto; Becton Dickinson, San Jose, CA) by counting 10,000 events.

\subsection{Cell cycle analysis by flow cytometry}

To determine the antiproliferative effects of $\mathrm{Fe}_{3} \mathrm{O}_{4} @ \mathrm{SiO}_{2}$ (FITC)-BTN/QUR, $\mathrm{Fe}_{3} \mathrm{O}_{4} @ \mathrm{SiO}_{2}$ (FITC)-BTN/DOX or $\mathrm{Fe}_{3} \mathrm{O}_{4} @ \mathrm{SiO}_{2}$ (FITC)-BTN/QUR/DOX nanoparticles against A549 and A549/DOX cells, cell cycle distributions were analyzed by flow cytometry-based propidium iodide (PI) staining. The cells $\left(1 \times 10^{5}\right.$ cells/well) were seeded in 6-well plates with $2 \mathrm{~mL}$ of growth medium overnight before experiments and then incubated with $\mathrm{IC}_{50}$ concentrations of the nanoparticle formulations for $24 \mathrm{~h}$ at
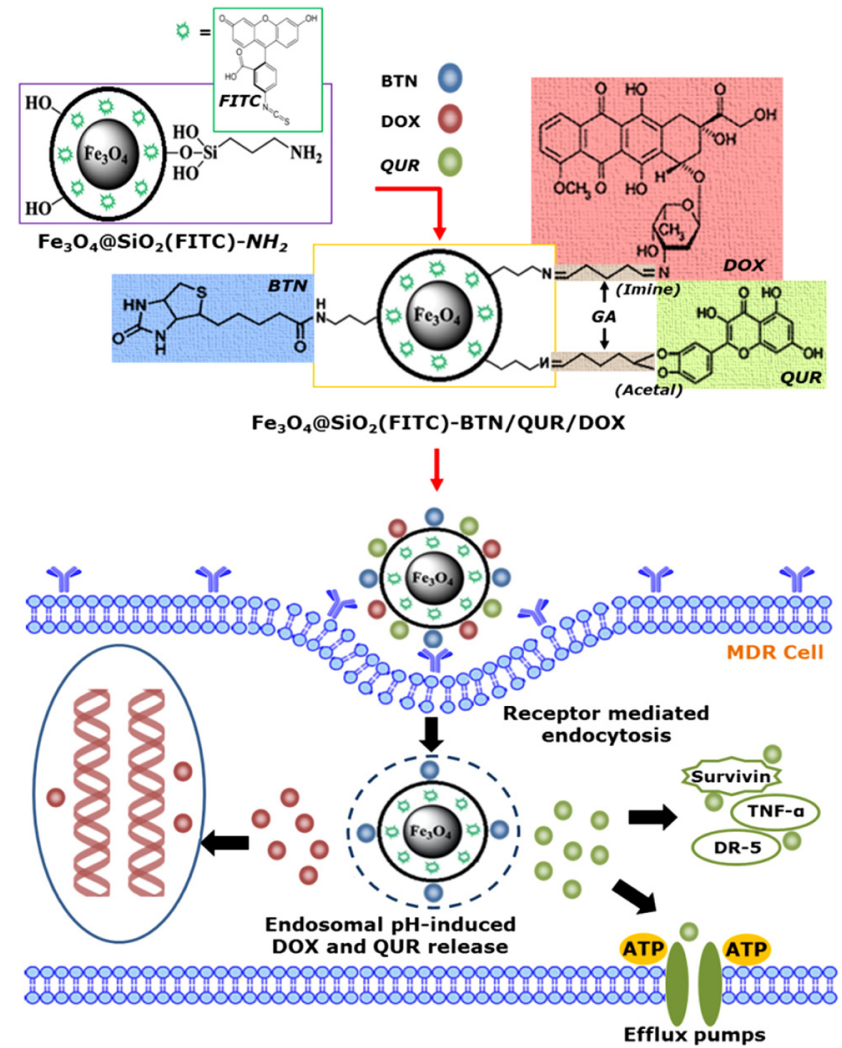

Fig. 1. Schematic representation of $\mathrm{Fe}_{3} \mathrm{O}_{4} @ \mathrm{SiO}_{2}$ (FITC)-BTN/QUR/DOX synthesis, targeted cell uptake and intracellular drug release.

$37^{\circ} \mathrm{C}$ under $5 \% \mathrm{CO}_{2}$. After incubation, the cells were trypsinized, washed once with PBS and fixed in $80 \%$ ethanol overnight at $-20^{\circ} \mathrm{C}$. The next day, after centrifugation of fixed cells, the pellet was washed with cold PBS and then resuspended in DNA staining solution [200 $\mu \mathrm{L} 0.1 \%$ Triton X-100 in PBS, $20 \mu \mathrm{L}(200 \mu \mathrm{g} / \mathrm{mL})$ RNase $A$ and $20 \mu \mathrm{L}(1 \mathrm{mg} / \mathrm{mL})$ propidium iodidel for $30 \mathrm{~min}$ at room temperature. The stained cells were analyzed using flow cytometer. The fraction of the G0-G1, S and G2-M phase of cells on DNA histograms was analyzed by ModFit software.

\subsection{Statistical analysis}

All data were represented as means \pm standard deviation (SD). Statistical analysis was performed with the Student's $t$-test, using Excel Software (Microsoft). A $P$ value of $\leq 0.05$ was considered statistically significant.

\section{Results and discussion}

\subsection{Synthesis and characterization of multifunctional nanoparticles}

The $\mathrm{Fe}_{3} \mathrm{O}_{4} @ \mathrm{SiO}_{2}$ (FITC)-BTN/QUR/DOX nanoparticles consisted of silica-coated luminomagnetic nanomaterials, triple conjugated to BTN, QUR and DOX. To construct the $\mathrm{Fe}_{3} \mathrm{O}_{4} @ \mathrm{SiO}_{2}$ (FITC)-BTN/NH nanoparticles, superparamagnetic $\left(\mathrm{Fe}_{3} \mathrm{O}_{4}\right)$ nanocrystals were synthesized by the co-precipitation method and coated with two silica shells for the incorporation of FITC by microemulsion sol-gel chemistry. The cancer targeting feature was then endowed by covalent bonding BTN on the surface of nanoparticles by means of an esterification reaction. Lastly, the silica surface was conjugated with QUR and DOX by pH-labile acetal and imine linkages for environmentally responsive drug release, with the expectation that these 
Table 1

Immobilization yields, size and zeta potential of the nanoparticle formulations.

\begin{tabular}{|c|c|c|c|c|}
\hline Nanoparticle formulations & $\begin{array}{l}\text { QUR and DOX } \\
\text { immobilization Yield (\%) }\end{array}$ & $\begin{array}{l}\text { QUR and DOX immobilization concentration } \\
\text { ( } \mu \text { M per mg nanoparticles) }\end{array}$ & Size $(\mathrm{nm})$ & Zeta potential $(\mathrm{mV})$ \\
\hline $\mathrm{Fe}_{3} \mathrm{O}_{4} @ \mathrm{SiO}_{2}(\mathrm{FITC})-\mathrm{BTN} / \mathrm{NH}_{2}$ & - & - & $32.4 \pm 5.2$ & $+8.6 \pm 3.3$ \\
\hline $\mathrm{Fe}_{3} \mathrm{O}_{4} @ \mathrm{SiO}_{2}$ (FITC)-BTN/QUR & 76.7 & 7.67 & $47.9 \pm 6.7$ & $-14.2 \pm 2.2$ \\
\hline $\mathrm{Fe}_{3} \mathrm{O}_{4} @ \mathrm{SiO}_{2}$ (FITC)-BTN/DOX & 94.3 & 0.94 & $55.2 \pm 7.0$ & $-14.7 \pm 2.0$ \\
\hline $\mathrm{Fe}_{3} \mathrm{O}_{4} @ \mathrm{SiO}_{2}$ (FITC)-BTN/QUR/DOX & $61.2_{(\mathrm{QUR})} / 58.7_{(\mathrm{DOX})}$ & $6.12_{(\mathrm{QUR})} / 0.59_{(\mathrm{DOX})}$ & $59.5 \pm 8.4$ & $-17.2 \pm 2.8$ \\
\hline
\end{tabular}
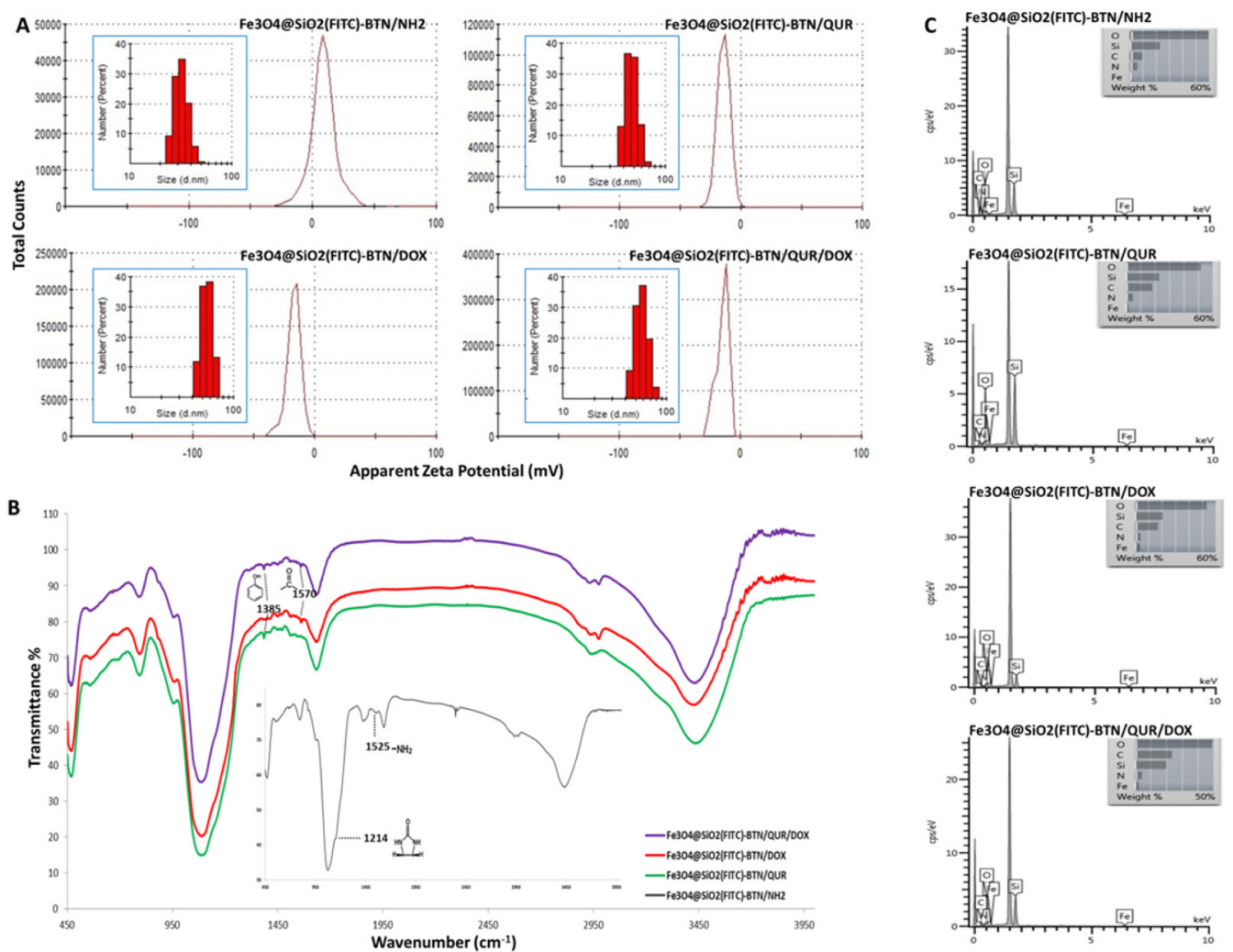

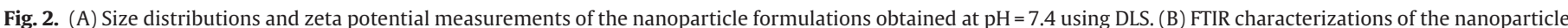

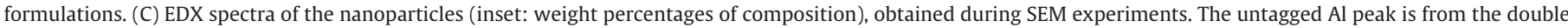
stick aluminum tape used in sample preparation.

acid-sensitive linkages would promote QUR and DOX release into the more acidic endosome of cancer cells instead of in the systemic circulation environment. The quantitative study of QUR and DOX conjugation on the silica surface showed that $6.12 \mu \mathrm{M}$ of QUR and $0.59 \mu \mathrm{M}$ of DOX were co-conjugated per mg $\mathrm{Fe}_{3} \mathrm{O}_{4} @ \mathrm{SiO}_{2}$ (FITC)BTN/QUR/DOX nanoparticles, while coupling yields of $7.67 \mu \mathrm{M}$ of QUR per mg $\mathrm{Fe}_{3} \mathrm{O}_{4} @ \mathrm{SiO}_{2}$ (FITC)-BTN/QUR and $0.94 \mu \mathrm{M}$ of DOX per mg $\mathrm{Fe}_{3} \mathrm{O}_{4} @ \mathrm{SiO}_{2}$ (FITC)-BTN/DOX were obtained (Table 1). The designed synthesis and anti-MDR strategy of the nanoparticles are schematically illustrated in Fig. 1.

The mean hydrodynamic size of the nanoparticle formulations were $32.4 \pm 5.2,47.9 \pm 6.7,55.2 \pm 7$ and $59.5 \pm 8.4 \mathrm{~nm}$ for $\mathrm{Fe}_{3} \mathrm{O}_{4} @ \mathrm{SiO}_{2}$ (FITC)-BTN $/ \mathrm{NH}_{2}, \quad \mathrm{Fe}_{3} \mathrm{O}_{4} @ \mathrm{SiO}_{2}$ (FITC)-BTN/QUR, $\mathrm{Fe}_{3} \mathrm{O}_{4} @ \mathrm{SiO}_{2}$ (FITC)-BTN/DOX and $\mathrm{Fe}_{3} \mathrm{O}_{4} @ \mathrm{SiO}_{2}$ (FITC)BTN/QUR/DOX nanoparticles, respectively, with narrow size distribution as demonstrated in Fig. 2a. To improve the biodistribution and circulation time of nanoparticles in the bloodstream, the sizes of the nanoparticles are of critical importance. Particles with a diameter ranging from 10 to $100 \mathrm{~nm}$ are optimal to prevent the uptake of nanoparticles by the ReticuloEndothelial System (RES) as well as for the endocytosis behavior of tumor cells [23]. The results suggest that these particles are small enough to carry and deliver their therapeutic payloads to cancer cells.
The zeta potential of nanoparticles was analyzed to confirm the change in their surface potential due to proper bioconjugation at different stages of synthesis (Fig. 2a and Table 1). The $\mathrm{Fe}_{3} \mathrm{O}_{4} @ \mathrm{SiO}_{2}$ (FITC)-BTN/NH $\mathrm{N}_{2}$ nanoparticles exhibited a positive zeta potential $(\zeta)$ value of $+8.6(\mathrm{pH} \mathrm{7.4)}$ ) due to presence of excess positively charged amino groups, which nullify the BTN charge and make the overall surface charge slightly positive.[15] Further surface functionalization of the nanoparticles by conjugating QUR and/or DOX led to an obvious charge reversion to $-14.2,-14.7$ and $-17.2 \mathrm{mV}$ values $(\mathrm{pH}=7.4)$ for $\mathrm{Fe}_{3} \mathrm{O}_{4} @ \mathrm{SiO}_{2}$ (FITC)BTN/QUR, $\mathrm{Fe}_{3} \mathrm{O}_{4} @ \mathrm{SiO}_{2}$ (FITC)-BTN/DOX and $\mathrm{Fe}_{3} \mathrm{O}_{4} @ \mathrm{SiO}_{2}$ (FITC)BTN/QUR/DOX nanoparticles, respectively, attributable to a function of the high ionizability of QUR and DOX groups on silica surface. The negatively charged properties of the nanoparticle formulations could reduce RES-mediated clearance and eliminate the adsorption of plasma protein; thereby, enhancing the blood circulation time with improved pharmacokinetic of therapeutics, which are essential for their biological applications.

In order to evaluate the success of the surface functionalization with BTN, QUR and DOX, Fourier transform infrared (FTIR) spectroscopy was used. For comparison, Fig. 2b gives the FTIR spectra of $\mathrm{Fe}_{3} \mathrm{O}_{4} @ \mathrm{SiO}_{2}$ (FITC)-BTN/NH $\mathrm{NH}_{2}, \mathrm{Fe}_{3} \mathrm{O}_{4} @ \mathrm{SiO}_{2}$ (FITC)- 

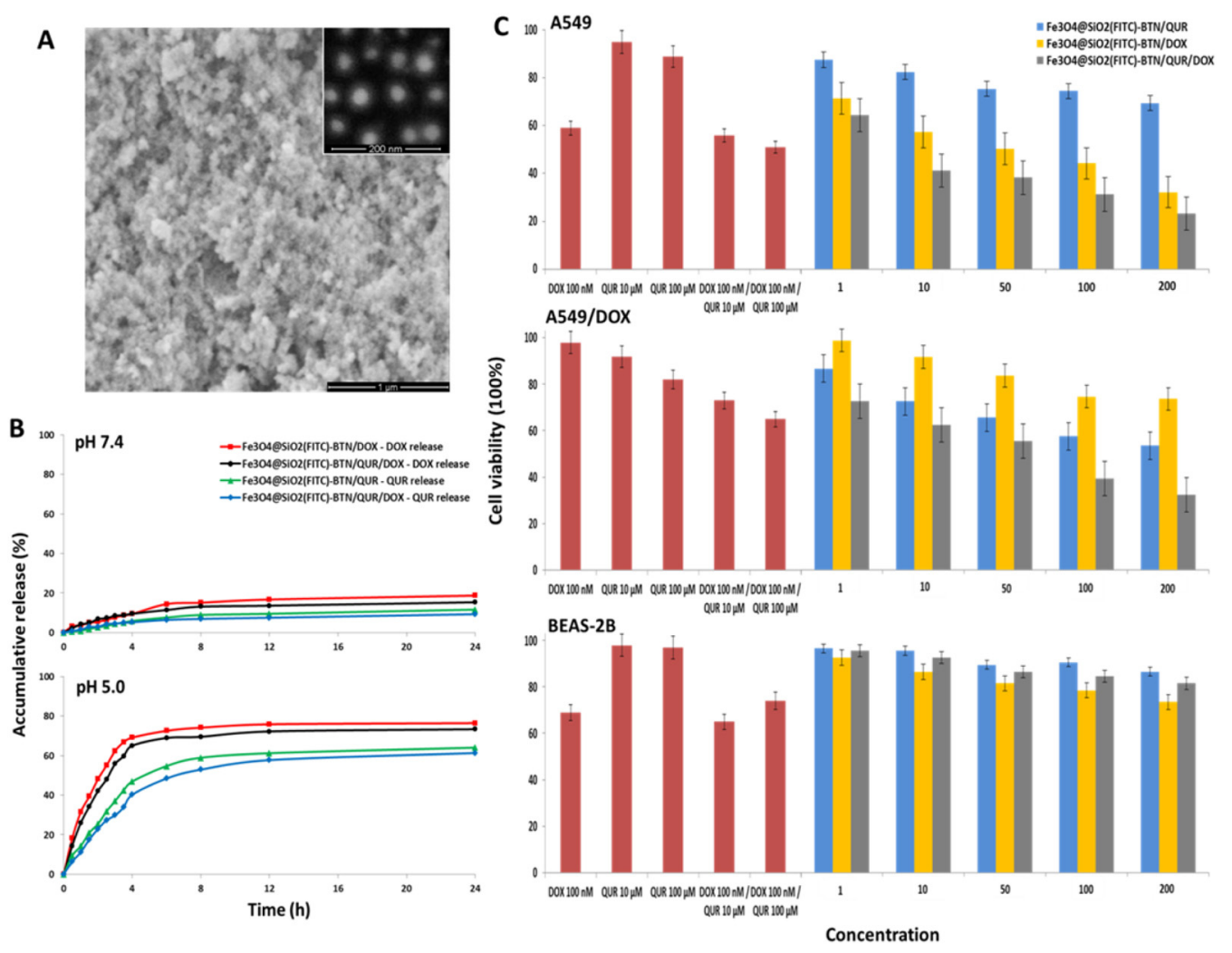

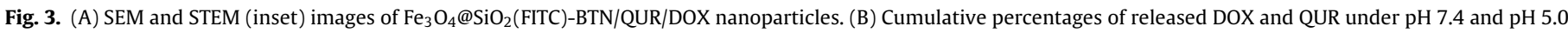

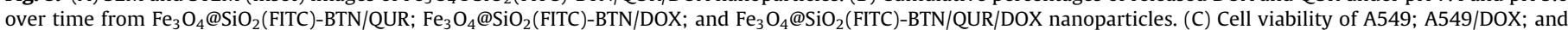

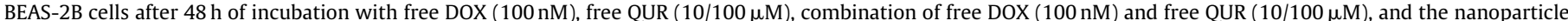

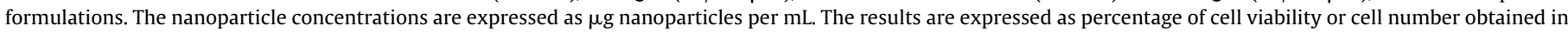
the untreated controls. Each column represents the mean \pm SD of three independent experiments performed in triplicate normalized to non-treated cells (taken as $100 \%$ ).

BTN/QUR, $\mathrm{Fe}_{3} \mathrm{O}_{4} @ \mathrm{SiO}_{2}$ (FITC)-BTN/DOX and $\mathrm{Fe}_{3} \mathrm{O}_{4} @ \mathrm{SiO}_{2}$ (FITC)BTN/QUR/DOX nanoparticles. The appearance of the absorption peaks at 1214 and $1525 \mathrm{~cm}^{-1}$ in the $\mathrm{Fe}_{3} \mathrm{O}_{4} @ \mathrm{SiO}_{2}$ (FITC)-BTN/NH FTIR spectrum confirms the existence of biotin [24] and the primary amine group of APTES [15] moieties, respectively. On the other hand, FTIR analysis of $\mathrm{Fe}_{3} \mathrm{O}_{4} @ \mathrm{SiO}_{2}$ (FITC)BTN/QUR, $\mathrm{Fe}_{3} \mathrm{O}_{4} @ \mathrm{SiO}_{2}$ (FITC)-BTN/DOX and $\mathrm{Fe}_{3} \mathrm{O}_{4} @ \mathrm{SiO}_{2}$ (FITC)BTN/QUR/DOX nanoparticles shows the presence of new bands at 1385 and $1570 \mathrm{~cm}^{-1}$, which are attributed to bending of the $\mathrm{O}-\mathrm{H}$ bond in aromatic hydrocarbon phenolic groups of QUR [25] and the stretching vibration of two carbonyl groups of the anthracene ring of DOX [15], respectively, indicated that QUR and DOX were successfully attached to the surface of the $\mathrm{Fe}_{3} \mathrm{O}_{4} @ \mathrm{SiO}_{2}$ (FITC)-BTN/NH nanoparticles.

The exterior morphology and interior structure of the synthesized $\mathrm{Fe}_{3} \mathrm{O}_{4} @ \mathrm{SiO}_{2}$ (FITC)-BTN/QUR/DOX nanoparticles were examined by SEM and STEM; and the respective chemical compositions at different fabrication stage were determined by EDX. SEM and STEM images show that the nanoparticles have nearly spherical shape and present a narrow size distribution (Fig. 3a). The core-shell structures can be easily recognized due to good contrast between the cores and the shell regions. The white cores are magnetic particles and the gray part is the silica shell. The thickness of the shell of the nanoparticles in dry state was about $50 \mathrm{~nm}$ which is almost in accordance to those found by DLS, indicating that the coated nanoparticles are stable and well dispersed in solution without aggregation or accumulation. The EDX analysis of the nanoparticle formulations clearly showed the progressive increase in $\mathrm{C}$ content and reduction in $\mathrm{N}$ content on the silica surfaces due
Table 2

Surface atomic percentages of the nanoparticles, obtained from EDX spectra.

\begin{tabular}{|c|c|c|c|c|c|}
\hline \multirow[t]{2}{*}{ The Nanoparticle Formulations } & \multicolumn{5}{|c|}{ Atomic (\%) } \\
\hline & $\mathrm{O}$ & $\mathrm{Si}$ & $\mathrm{C}$ & $\mathrm{N}$ & $\mathrm{Fe}^{*}$ \\
\hline $\mathrm{Fe}_{3} \mathrm{O}_{4} @ \mathrm{SiO}_{2}(\mathrm{FITC})-\mathrm{BTN} / \mathrm{NH}_{2}$ & 63.9 & 14.3 & 14.1 & 7.5 & 0.2 \\
\hline $\mathrm{Fe}_{3} \mathrm{O}_{4} @ \mathrm{SiO}_{2}$ (FITC)-BTN/QUR & 54.2 & 13.7 & 26.9 & 4.8 & 0.4 \\
\hline $\mathrm{Fe}_{3} \mathrm{O}_{4} @ \mathrm{SiO}_{2}$ (FITC)-BTN/DOX & 56.3 & 12.5 & 26.4 & 4.4 & 0.8 \\
\hline $\mathrm{Fe}_{3} \mathrm{O}_{4} @ \mathrm{SiO}_{2}$ (FITC)-BTN/QUR/DOX & 50.1 & 11.7 & 33.5 & 4.2 & 0.5 \\
\hline
\end{tabular}

${ }^{*}$ Fe content is detected due to the penetration depth of the X-ray beam through the thick silica shell.

to organic functionalities which are gradually enriched by iterative chemical conjugation (Fig. 2c and Table 2).

\subsection{In vitro $\mathrm{pH}$-stimuli release study}

The nanoparticles were formulated for $\mathrm{pH}$-sensitive drug release to control the release of the conjugated therapeutics based on local $\mathrm{pH}$ levels. Thus, the nanoparticles are expected to retain the drug combination during circulation while actively releasing them inside the target tumor cells. For this reason, the ability of the nanoparticles to release the conjugated therapeutics at pH 7.4 and 5.0 was tested to simulate the physiological $\mathrm{pH}$ in the blood circulation and the acidic $\mathrm{pH}$ in endosome of tumor cells. Most of the drugs were released from the nanoparticle formulations within a few hours at $\mathrm{pH} 5.0$, whilst the nanoparticles showed no more than $18 \%$ of the conjugated drugs release at $\mathrm{pH} 7.4$ for $24 \mathrm{~h}$, implying that pH-labile conjugation exerted a dominant influence on preventing the premature 


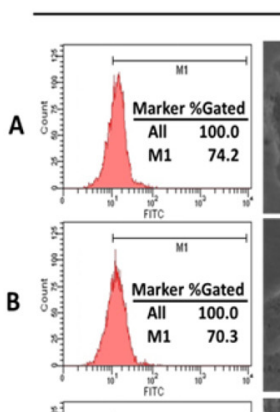

A549- $4 \mathrm{~h}$
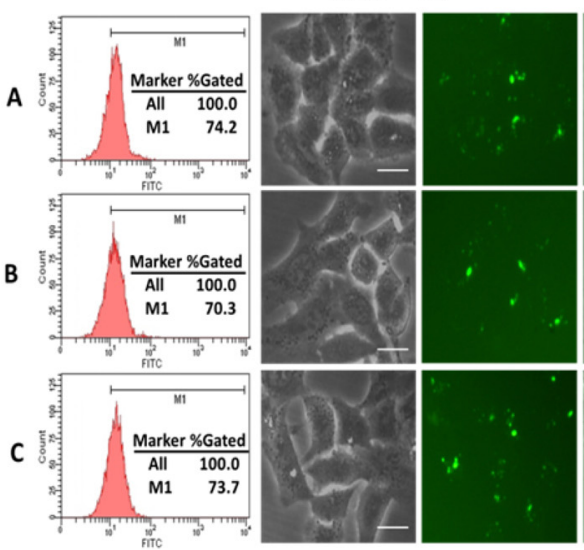

A549/DOX $-4 \mathrm{~h}$
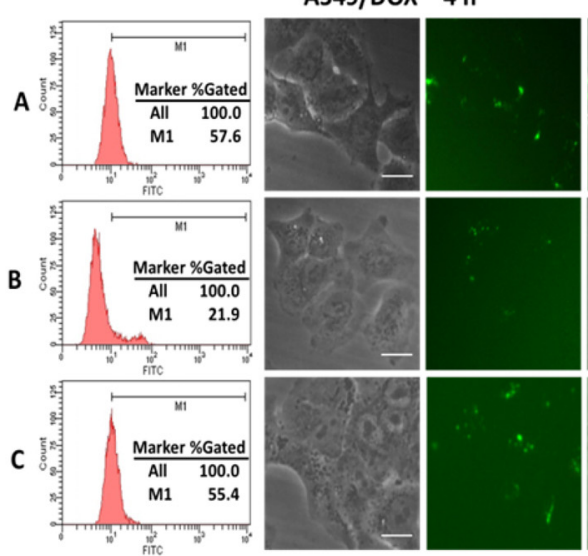

BEAS-2B / $4 \mathrm{~h}$
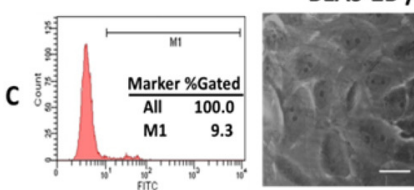

1

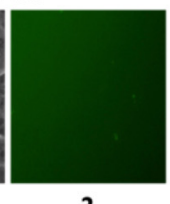

2
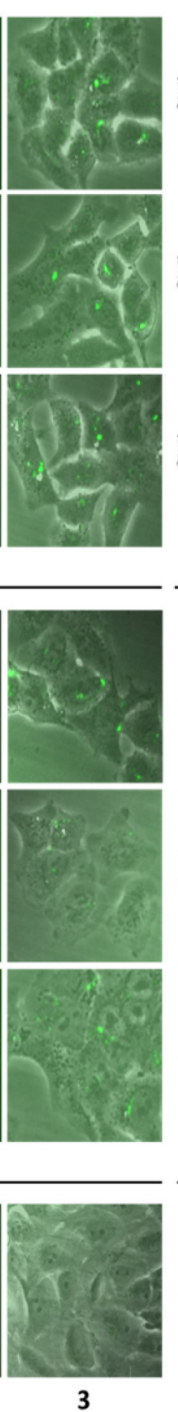

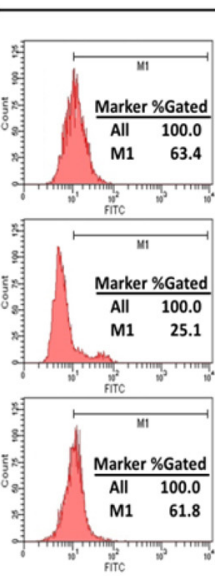

A549-24 h
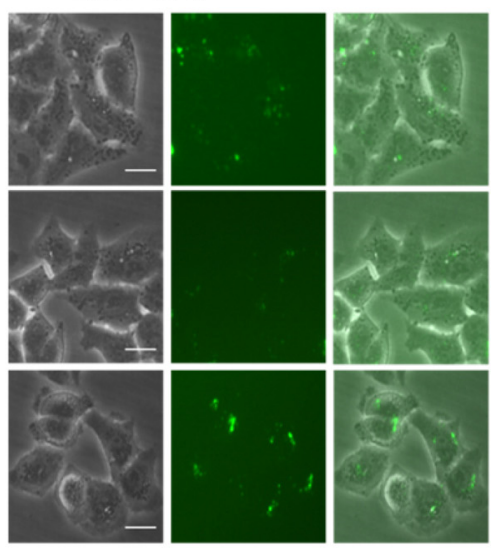

A549/DOX - $24 \mathrm{~h}$
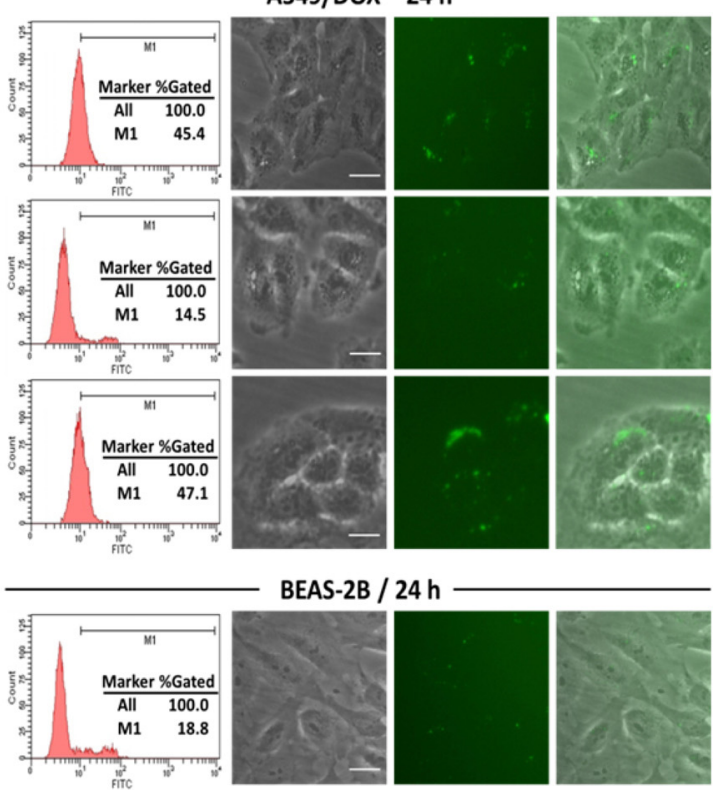

BEAS-2B / $24 \mathrm{~h}$

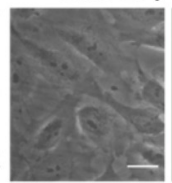

1

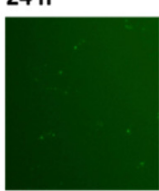

2

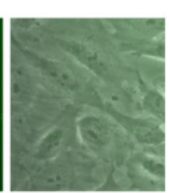

3

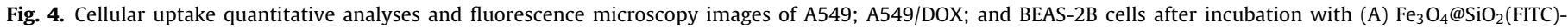

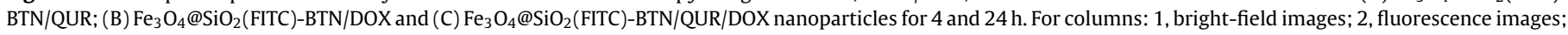
and 3 , the merger of both. Scale bar: $40 \mu \mathrm{m}$.

drug release. During the first $4 \mathrm{~h}$ under $\mathrm{pH} 5.0$, the release of DOX from $\mathrm{Fe}_{3} \mathrm{O}_{4} @ \mathrm{SiO}_{2}$ (FITC)-BTN/DOX and $\mathrm{Fe}_{3} \mathrm{O}_{4} @ \mathrm{SiO}_{2}$ (FITC)BTN/QUR/DOX nanoparticles showed release of 69 and $65 \%$, respectively. After $24 \mathrm{~h}$, the cumulative amount of DOX released increased to 75 and $73 \%$ from the corresponding nanoparticles. Furthermore, the release of QUR from $\mathrm{Fe}_{3} \mathrm{O}_{4} @ \mathrm{SiO}_{2}$ (FITC)-BTN/QUR and $\mathrm{Fe}_{3} \mathrm{O}_{4} @ \mathrm{SiO}_{2}$ (FITC)-BTN/QUR/DOX nanoparticles exhibited a similar release pattern to that of DOX: approximately 47 and $40 \%$ of QUR were released in $4 \mathrm{~h}$ under $\mathrm{pH}$ 5.0, whereas the cumulative percentages were improved to 64 and $61 \%$ after $24 \mathrm{~h}$, respectively from the corresponding nanoparticles (Fig. 3b).

In general, the controlled transport of drugs has been mostly achieved by loading them into nanocarriers. Even if these carriers entrap high amounts of therapeutics and accumulate inside the tumor, they may not be able to release the drug to kill malignant cells (especially drug-resistant cells) in time, as the drugs slowly diffuse from the nanoparticle core [26]. To eliminate this obstacle, conjugating the drugs to the nanoparticle surface with sensitive linkage could lead to fast intracellular drug release and a high level intracellular drug concentration to achieve the effective therapeutic concentration for reversing the MDR efflux function.

\subsection{Cellular uptake}

The cellular uptake behaviors and resistance reversing abilities of nanoparticle formulations were examined in drug-sensitive A549, drug-resistant A549/DOX and non-tumoral BEAS-2B cells by fluorescence microscope and flow cytometry (Fig. 4).

For drug-sensitive A549 cells with a relatively low expression of MDR proteins, green fluorescence was observed from the images of $\mathrm{Fe}_{3} \mathrm{O}_{4} @ \mathrm{SiO}_{2}$ (FITC)-BTN/QUR, $\mathrm{Fe}_{3} \mathrm{O}_{4} @ \mathrm{SiO}_{2}$ (FITC)-BTN/DOX and $\mathrm{Fe}_{3} \mathrm{O}_{4} @ \mathrm{SiO}_{2}$ (FITC)-BTN/QUR/DOX nanoparticles at $4 \mathrm{~h}$ with no significant differences with $74.2,70.3$ and $73.7 \%$ cellular uptake efficiencies, respectively, which indicated that the vectorized nanoparticles with BTN successfully penetrated into the cells. After prolonging incubation periods to $24 \mathrm{~h}$, the fluorescence intensity (25.1\%) from $\mathrm{Fe}_{3} \mathrm{O}_{4} @ \mathrm{SiO}_{2}$ (FITC)-BTN/DOX nanoparticles obviously decreased as compared with both $\mathrm{Fe}_{3} \mathrm{O}_{4} @ \mathrm{SiO}_{2}$ (FITC)-BTN/QUR (63.4\%) and $\mathrm{Fe}_{3} \mathrm{O}_{4} @ \mathrm{SiO}_{2}$ (FITC)-BTN/QUR/DOX (61.8\%) intensities. 
Table 3

The IC $\mathrm{I}_{50}$ values of the nanoparticles in A549, A549/DOX and BEAS-2B cells when incubated for 48 h. N.A. = Not Applicable (the data cannot be fitted as not enough inhibition was observed) in the cells. Values represent the mean $\pm S D$ of three independent experiments.

\begin{tabular}{llll}
\hline Nanoparticle formulations $(\mu \mathrm{g} / \mathrm{mL})$ & A549 & A549/DOX & BEAS-2B \\
\hline $\mathrm{Fe}_{3} \mathrm{O}_{4} @ \mathrm{SiO}_{2}$ (FITC)-BTN/QUR & $421.2 \pm 8.4$ & $191.7 \pm 5.4$ & N.A. \\
$\mathrm{Fe}_{3} \mathrm{O}_{4} @ \mathrm{SiO}_{2}$ (FITC)-BTN/DOX & $55.0 \pm 3.7$ & $362.1 \pm 8.8$ & $\geq 500$ \\
$\mathrm{Fe}_{3} \mathrm{O}_{4} @ \mathrm{SiO}_{2}$ (FITC)-BTN/QUR/DOX & $14.4 \pm 2.3$ & $61.1 \pm 4.1$ & N.A. \\
\hline
\end{tabular}

This reduction was due to overexpression of MDR proteins, which demonstrated that the sensitization effect of QUR was successfully overcoming drug resistance. On the other hand, in spite of the development of drug resistance in cancer cells, the weak green fluorescence, which was still visible in the cells incubated with $\mathrm{Fe}_{3} \mathrm{O}_{4} @ \mathrm{SiO}_{2}$ (FITC)-BTN/DOX nanoparticles after $24 \mathrm{~h}$, corroborated that rationally designed nanoparticles are capable of minimizing drug expulsion by efflux pumps and leading to a persistent intracellular accumulation and effectiveness.

For the drug-resistance A549/DOX cells, the fluorescence intensity of $\mathrm{Fe}_{3} \mathrm{O}_{4} @ \mathrm{SiO}_{2}$ (FITC)-BTN/DOX nanoparticles (21.9\% for $4 \mathrm{~h}$; $14.5 \%$ for $24 \mathrm{~h}$ ) was very low from $\mathrm{Fe}_{3} \mathrm{O}_{4} @ \mathrm{SiO}_{2}$ (FITC)-BTN/QUR ( $57.6 \%$ for $4 \mathrm{~h} ; 45.4 \%$ for $24 \mathrm{~h}$ ) and $\mathrm{Fe}_{3} \mathrm{O}_{4} @ \mathrm{SiO}_{2}$ (FITC)-BTN/QUR/DOX ( $55.4 \%$ for $4 \mathrm{~h} ; 47.1 \%$ for $24 \mathrm{~h}$ ) nanoparticles in both 4 and $24 \mathrm{~h}$ incubation periods due to the high MDR efflux function. In contrast, the nanoparticle formulations conjugated with QUR showed consistent fluorescence which supports intracellular stability and accumulation of the nanoparticles even after $24 \mathrm{~h}$, confirming QUR's functional involvement in reversing MDR. Furthermore, $\mathrm{Fe}_{3} \mathrm{O}_{4} @ \mathrm{SiO}_{2}$ (FITC)-BTN/QUR/DOX nanoparticle uptake was minimal in normal BEAS-2B lung cells during the 4 and $24 \mathrm{~h}$ incubations (9.3 and $18.8 \%$, respectively), confirming that the nanoparticles facilitate internalization into tumor cells but not normal cells. Overall, these results confirmed the necessity of BTN and QUR in $\mathrm{Fe}_{3} \mathrm{O}_{4} @ \mathrm{SiO}_{2}$ (FITC)-BTN/QUR/DOX nanoparticles to achieve true molecular targeting of cancer cells and inhibition of the MDR-efflux activity, respectively.

\subsection{Cytotoxicity of the multifunctional nanoparticles}

To examine the restoring effect of QUR on DOX cytotoxicity toward drug-sensitive A549, drug-resistant A549/DOX and non-tumoral BEAS-2B cells, the cell inhibitory effects of the nanoparticle formulations and free drug combinations were investigated using MTT cell proliferation assay. Among all nanoparticles tested, $\mathrm{Fe}_{3} \mathrm{O}_{4} @ \mathrm{SiO}_{2}$ (FITC)-BTN/QUR/DOX nanoparticles exhibited stronger cell inhibitory effects with approximately 3.8- and 29.2-fold lower $\mathrm{IC}_{50}$ values in A549 cells as compared to $\mathrm{Fe}_{3} \mathrm{O}_{4} @ \mathrm{SiO}_{2}$ (FITC)-BTN/DOX and $\mathrm{Fe}_{3} \mathrm{O}_{4} @ \mathrm{SiO}_{2}$ (FITC)-BTN/QUR nanoparticles, respectively. Importantly the nanoparticles were notably more toxic (5.9-fold) than $\mathrm{Fe}_{3} \mathrm{O}_{4} @ \mathrm{SiO}_{2}$ (FITC)-BTN/DOX nanoparticles while moderately more toxic (3.1-fold) than $\mathrm{Fe}_{3} \mathrm{O}_{4} @ \mathrm{SiO}_{2}$ (FITC)-BTN/QUR nanoparticles in A549/DOX cells, demonstrating the high potential of the nanoparticles for treating drug-resistant lung cancer (Table 3 ). This data showed that $\mathrm{Fe}_{3} \mathrm{O}_{4} @ \mathrm{SiO}_{2}$ (FITC)-BTN/QUR/DOX nanoparticles led to an obvious inhibition concentration reversion in drug-resistant A549/DOX cells to the $\mathrm{IC}_{50}$ value used in drug-sensitive A549 cells for $\mathrm{Fe}_{3} \mathrm{O}_{4} @ \mathrm{SiO}_{2}$ (FITC)-BTN/DOX nanoparticles. Moreover, $\mathrm{Fe}_{3} \mathrm{O}_{4} @ \mathrm{SiO}_{2}$ (FITC)-BTN/QUR nanoparticles demonstrated a higher cytotoxicity in A549/DOX cells with an approximately 2.2-fold better $\mathrm{IC}_{50}$ value than $\mathrm{A} 549$ cells, thus confirming the function of QUR in reversing cancer MDR. $\mathrm{Fe}_{3} \mathrm{O}_{4} @ \mathrm{SiO}_{2}$ (FITC)-BTN/QUR/DOX nanoparticles did not affect normal lung cell growth even at high concentration $(200 \mu \mathrm{g} / \mathrm{mL})$ and exhibited decreased DOX- mediated cytotoxicity as compared to $\mathrm{Fe}_{3} \mathrm{O}_{4} @ \mathrm{SiO}_{2}$ (FITC)-BTN/DOX nanoparticles (Fig. 3c).

In further cytotoxicity studies, the cells were exposed to $100 \mathrm{nM}$ free DOX, representing the mean plasma concentration of doxorubicin in patients under chemotherapy, which was approximately 3 times higher than the DOX concentration in $50 \mu \mathrm{g} / \mathrm{mL}$ of $\mathrm{Fe}_{3} \mathrm{O}_{4} @ \mathrm{SiO}_{2}$ (FITC)-BTN/QUR/DOX nanoparticles; to $10 \mu \mathrm{M}$ and $100 \mu \mathrm{M}$ free QUR, which correspond to approximately 30- and 300 -fold increased QUR concentrations compared to $50 \mu \mathrm{g} / \mathrm{mL}$ of $\mathrm{Fe}_{3} \mathrm{O}_{4} @ \mathrm{SiO}_{2}$ (FITC)-BTN/QUR/DOX nanoparticles, respectively; or to combinations of $100 \mathrm{nM}$ free DOX with $10 \mu \mathrm{M}$ and $100 \mu \mathrm{M}$ free QUR, respectively. As shown in Fig. 3C, $\mathrm{Fe}_{3} \mathrm{O}_{4} @ \mathrm{SiO}_{2}$ (FITC)BTN/QUR/DOX nanoparticles with notably lower drug concentrations exhibited remarkably higher cytotoxicity than that exhibited by the combinations of the free DOX and free QUR in both A549 and A549/DOX cells. Free QUR showed more dose dependent inhibition in A549/DOX cells than in A549 cells, but was not as cytotoxic as the nanoparticle formulations in reversing cancer MDR. Furthermore, free QUR did not decrease the cytotoxic effect of free DOX with both concentrations in BEAS-2B cells when compared with the nanoparticle formulations, most likely due to its low solubility.

We have previously demonstrated that neutralizing the action of survivin (BIRC5) potentiates the efficacy of DOX against chemoresistance $[15,16]$. Similarly in this work, QUR, as a potential survivin suppressor within its MDR-modulating activity[11,12], not only potentiated the efficacy of DOX in A549 and A549/DOX cells but also sensitized drug resistant A549/DOX cells to DOX chemotherapy, while attenuating DOX-mediated cytotoxicity in non-tumoral BEAS-2B cells. Staedleret et al. also reported that QUR enhances the therapeutic efficacy of doxorubicin in highly invasive breast cancer cells and simultaneously reduces doxorubicin-induced toxic side effects [27]. In addition, Kaiserova et al. showed that QUR lowers DOX-induced toxicity by chelating iron, inducing antioxidant activity and inhibiting carbonyl reductase [28]. These observations suggest that $\mathrm{Fe}_{3} \mathrm{O}_{4} @ \mathrm{SiO}_{2}$ (FITC)-BTN/QUR/DOX nanoparticles may be recognized as a promising approach to improve bioactivity of QUR and the therapeutic index of DOX, which are capable of inducing cytotoxicity in drug-resistant cancer cells, while producing negligible effects on normal cells.

\subsection{Detection of apoptotic cells by flow cytometry}

To investigate the apoptosis-inducing ability of the nanoparticle formulations in drug-sensitive A549 and drug-resistant A549/DOX cells, and to examine whether QUR can enhance sensitivity to DOX treatment, the percentage of cells undergoing apoptosis was analyzed by flow cytometry with 7-ADD and PE-annexin-V double staining. $\mathrm{Fe}_{3} \mathrm{O}_{4} @ \mathrm{SiO}_{2}$ (FITC)-BTN/QUR/DOX nanoparticles, versus the other nanoparticles, strongly increased the percent of late apoptotic cells $\left(\mathrm{ADD}^{+} / \mathrm{PE}-\mathrm{V}^{+}\right)$in A549 and A549/DOX cells to 93.9 and $69.8 \%$. When cells were exposed to $\mathrm{Fe}_{3} \mathrm{O}_{4} @ \mathrm{SiO}_{2}$ (FITC)-BTN/DOX nanoparticles, the number of late apoptotic cells in drug-resistant A549/DOX cells was $10.8 \%$, which was significantly lower than the apoptosis rate (76.5\%) in drug-sensitive A549 cells due to the high MDR activity. In addition, the number of early apoptotic cells $\left(\mathrm{ADD}^{-} / \mathrm{PE}-\mathrm{V}^{+}\right)$in A549/DOX cells $(35.3 \%)$ was 4.3 times higher than in A549 cells (8.2\%), suggesting that MDR proteins interfered with the efficacy of DOX-chemotherapy and led to prolonged initial phase of apoptosis. On the other hand, treatment with $\mathrm{Fe}_{3} \mathrm{O}_{4} @ \mathrm{SiO}_{2}$ (FITC)-BTN/QUR nanoparticles showed considerable apoptotic effect in both A549 and A549/DOX cells with total apoptotic percentages of 66.3 and $76.7 \%$, respectively (Fig. 5a). Overall these results demonstrated that $\mathrm{Fe}_{3} \mathrm{O}_{4} @ \mathrm{SiO}_{2}$ (FITC)-BTN/QUR/DOX nanoparticles clearly potentiate the DOX-induced apoptosis in drug-resistant A549/DOX cells by modulating MDR proteins, while synergistically sensitizing A549 cells to DOX-chemotherapy, 
A

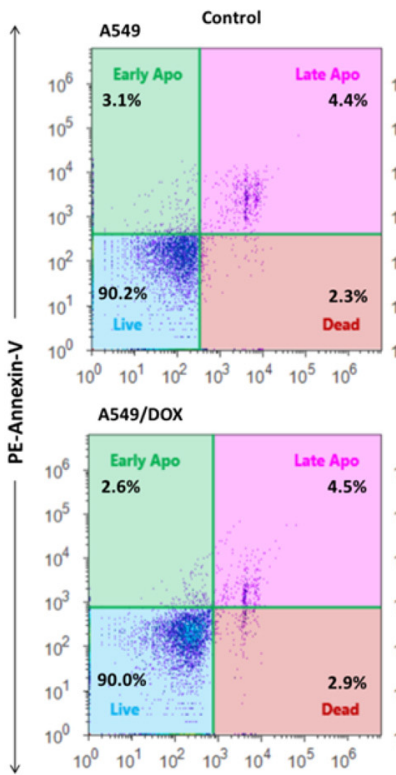

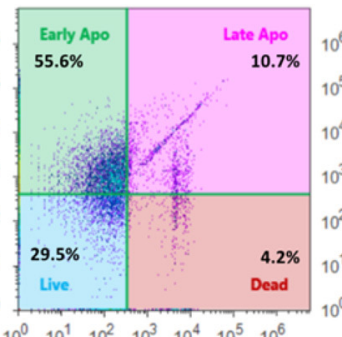

$\begin{array}{llllllll}10^{0} & 10^{1} & 10^{2} & 10^{3} & 10^{4} & 10^{5} & 10^{6}\end{array}$

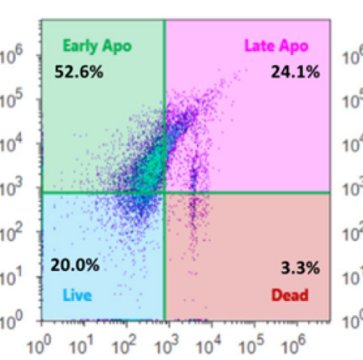

Fe3O4@SIO2(FITC)-BTN/DOX

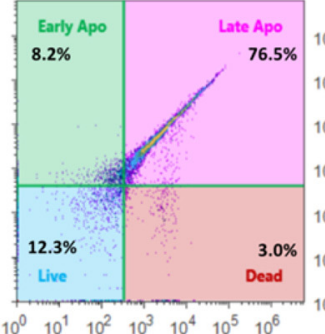

$\begin{array}{lllllllllllllll}10^{0} & 10^{1} & 10^{2} & 10^{3} & 10^{4} & 10^{5} & 10^{6} & 10^{0} & 10^{1} & 10^{2} & 10^{3} & 10^{4} & 10^{5} & 10^{6}\end{array}$

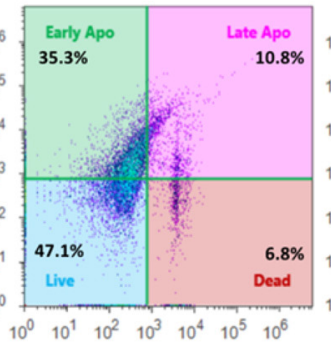

Fe304@SIO2(FITC)-BTN/QUR/DOX
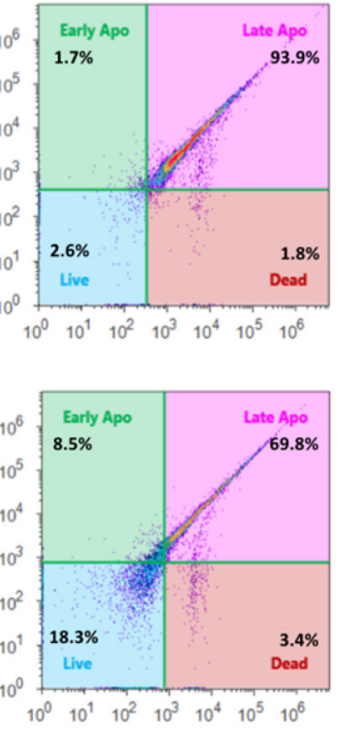

B

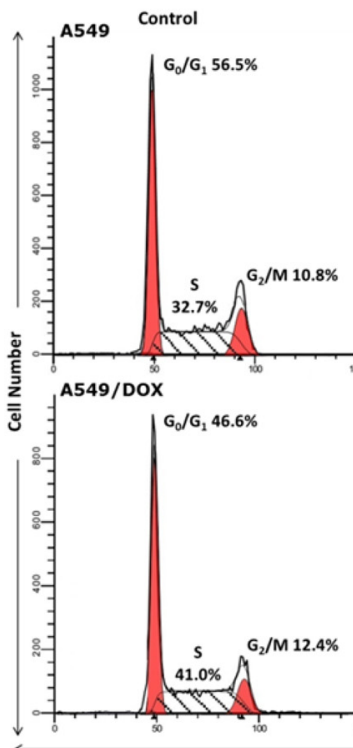

Fe3O4@SIO2(FITC)-BTN/QUR
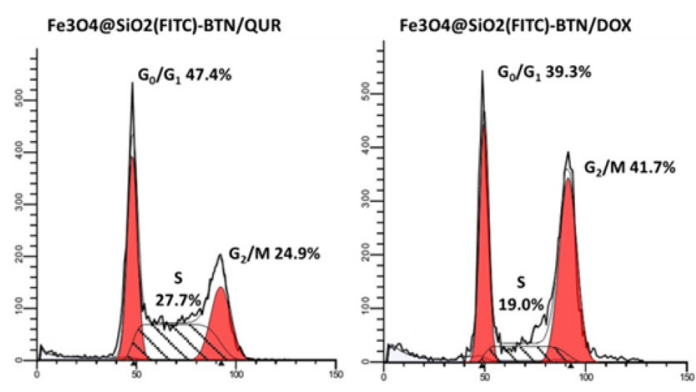

Fe304@SiO2(FITC)-BTN/QUR/DOX

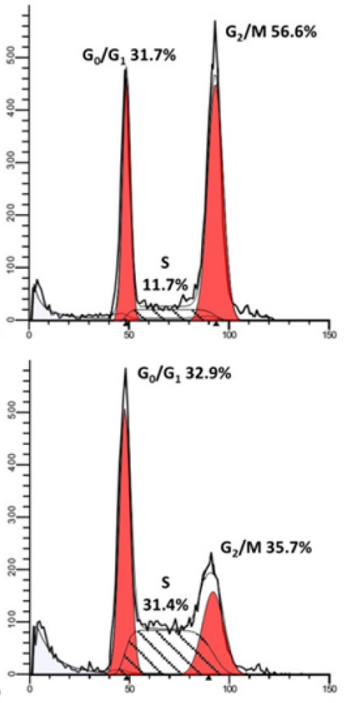

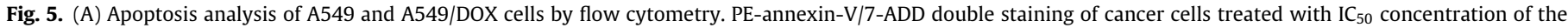

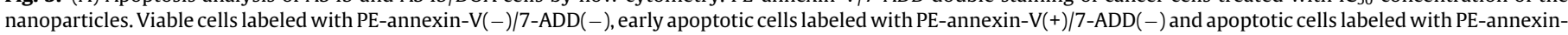

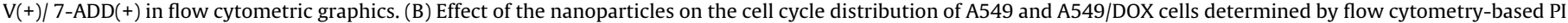
staining. Non-treated cells were used as control.

confirming the potentiation effect of QUR on drug-mediated cytotoxicity in cancer cells.

\subsection{Cell cycle analysis by flow cytometry}

To further determine the possible involvement of nanoparticle formulations in the regulation of the cell cycle, with the expectation that synergistic inhibition of the cells would promote the antiproliferative effect, the cell cycle phase distribution of drug-sensitive A549 and drug-resistant A549/DOX cells was examined by flow cytometry. Exposure of A549 cells to $\mathrm{Fe}_{3} \mathrm{O}_{4} @ \mathrm{SiO}_{2}$ (FITC)-BTN/QUR/DOX nanoparticles significantly depressed cell proliferation in the $\mathrm{G}_{2} / \mathrm{M}$ checkpoint (56.6\%), compared to the $\mathrm{Fe}_{3} \mathrm{O}_{4} @ \mathrm{SiO}_{2}$ (FITC)-BTN/QUR (24.9\%) and $\mathrm{Fe}_{3} \mathrm{O}_{4} @ \mathrm{SiO}_{2}$ (FITC)-BTN/DOX (41.7\%) nanoparticles. These data indicated that the effects of QUR and DOX conjugated nanoparticles in the antiproliferative action are more significant than those of the nanoparticles conjugated with QUR and DOX alone. Importantly, the pattern of cell cycle distribution of drug-resistant A549/DOX cells treated with $\mathrm{Fe}_{3} \mathrm{O}_{4} @ \mathrm{SiO}_{2}$ (FITC)BTN/QUR/DOX nanoparticles showed a considerably higher percentage of cells at $\mathrm{G} 2 / \mathrm{M}$ phase (35.7\%) in comparison to untreated control cells (12.4\%). Similar results for $\mathrm{G}_{2} / \mathrm{M}$ arrest (23\%) were observed following $\mathrm{Fe}_{3} \mathrm{O}_{4} @ \mathrm{SiO}_{2}$ (FITC)-BTN/QUR nanoparticle treatment, whereas $\mathrm{Fe}_{3} \mathrm{O}_{4} @ \mathrm{SiO}_{2}$ (FITC)-BTN/DOX nanoparticles hardly arrested A549/DOX cells (14.2\%) in G2/M phase of the cell cycle. These results indicate that QUR induce antiproliferative response better than DOX treatment, and their combination has superior antiproliferative activity against drug-resistant A549/DOX cells (Fig. 5b). These results demonstrated that, besides its proapop- 
totic effects, the $\mathrm{Fe}_{3} \mathrm{O}_{4} @ \mathrm{SiO}_{2}$ (FITC)-BTN/QUR/DOX nanoparticles also show antiproliferative activity in both A549 and A49/DOX cells via $\mathrm{G}_{2} / \mathrm{M}$-phase arrest.

\section{Conclusions}

In summary, $\mathrm{Fe}_{3} \mathrm{O}_{4} @ \mathrm{SiO}_{2}$ (FITC)-BTN/QUR/DOX multifunctional nanoparticles were fabricated for environmentally responsive codelivery of QUR and DOX as a way of reversing MDR. The structures of the nanoparticles were confirmed by different characterization techniques: DLS, FTIR, EDX, SEM and STEM. The conjugation of QUR and DOX to the surface of nanoparticles via pH-labile linkages led to 6.7- and 4.8-fold improved release at $\mathrm{pH} 5$ versus $\mathrm{pH}$ 7.4, respectively, an important improvement in this drug delivery model. These findings also show that the conjugation of QUR on the surface of nanoparticles helped to increase the bioavailability of QUR in tumor cells which resulted in an increased chemosensitivity of drug-resistant cells to DOX chemotherapy and rendered improved pharmacokinetic and drug performance properties.

$\mathrm{Fe}_{3} \mathrm{O}_{4} @ \mathrm{SiO}_{2}$ (FITC)-BTN/QUR/DOX nanoparticles potentiated the efficacy of DOX with higher sensitivity in drug-resistant A549/DOX cells compared to its parent counterpart A549 cells, while attenuating DOX-mediated cytotoxicity in non-tumoral BEAS-2B cells. Cellular uptake studies confirmed that the designed nanoparticles are capable of minimizing drug expulsion by efflux pumps and lead to a persistent intracellular accumulation. Moreover, it was found that the combination effect of DOX and QUR within a multifunctional platform maximized apoptosis and G2/M-phase cell cycle arrest in both A549 and A549/DOX cells, compared to treatment with nanoparticles containing only QUR or DOX alone, thereby confirming the synergistic effect of this combination in reduction of resistance-mediating factors. In particular, the conjugation of QUR with DOX led to approximately 6- and 10-fold decreases in DOX concentrations against drugsensitive A549 and drug-resistant A549/DOX cells, respectively. This reduction allowed the use of a low-dose chemotherapeutic agent without the need for dose increment; a significant finding in a clinical context.

These observations show that the $\mathrm{Fe}_{3} \mathrm{O}_{4} @ \mathrm{SiO}_{2}$ (FITC)BTN/QUR/DOX nanoparticles orchestrate multiple functions simultaneously, including: (a) enhancing DOX uptake and bioavailability of QUR into tumor cells via active targeting strategy and nanotechnology; (b) the pH-responsive nanoparticles can readily activated within tumor cells via its acid-sensitive drug release profile; (c) reducing DOX efflux from tumor cells which is often mediated by $A B C$ transporter family; (d) modulating signaling pathways to sensitize tumor cells to DOX chemotherapy; and (e) activating the antioxidant defense of normal cells against DOX cytotoxicity via the inherent property of QUR. Overall, it can be concluded that this therapeutic strategy which combines QUR and DOX within a multifunctional platform might be promising against MDR by increasing the therapeutic index of chemotherapeutics.

\section{Funding}

This research did not receive any specific grant from funding agencies in the public, commercial, or not-for-profit sectors.

\section{Acknowledgments}

I would like to thank Professor Anne Frary at the Izmir Institute of Technology for proofreading the manuscript and all members of The Center for Materials Research and Biotechnology and Bioengi- neering Center of Izmir Institute of Technology for their technical support.

\section{References}

[1] C. Holohan, S. Van Schaeybroeck, D.B. Longley, P.G. Johnston, Cancer drug resistance: an evolving paradigm, Nat. Rev. Cancer 13 (2013) 714-726.

[2] M.M. Gottesman, T. Fojo, S.E. Bates, Multidrug resistance in cancer: role of ATP-dependent transporters, Nat. Rev. Cancer 2 (2002) 48-58.

[3] S.V. Ambudkar, S. Dey, C.A. Hrycyna, M. Ramachandra, I. Pastan, M.M. Gottesman, Biochemical, cellular, and pharmacological aspects of the multidrug transporter, Annu. Rev. Pharmacol. Toxicol. 39 (1999) 361-398.

[4] Q. Yin, J. Shen, Z. Zhang, H. Yu, Y. Li, Reversal of multidrug resistance by stimuli-responsive drug delivery systems for therapy of tumor, Adv. Drug Delivery Rev. 65 (2013) 1699-1715.

[5] R. Krishna, L.D. Mayer, Multidrug resistance (MDR) in cancer, Mechanisms, reversal using modulators of MDR and the role of MDR modulators in influencing the pharmacokinetics of anticancer drugs, Eur. J. Pharm. Sci. 11 (2000) 265-283.

[6] D.R. Ferry, H. Traunecker, D.J. Kerr, Clinical trials of P-glycoprotein reversal in solid tumours, Eur. J. Cancer 32A (1996) 1070-1081.

[7] L.D. Cripe, H. Uno, E.M. Paietta, M.R. Litzow, R.P. Ketterling, J.M. Bennett, J.M. Rowe, H.M. Lazarus, S. Luger, M.S. Tallman, Zosuquidar, a novel modulator of P-glycoprotein, does not improve the outcome of older patients with newly diagnosed acute myeloid leukemia: a randomized, placebo-controlled trial of the eastern cooperative oncology group 3999, Blood 116 (2010) 4077-4085.

[8] L. Le Marchand, Cancer preventive effects of flavonoids-a review, Biomed. Pharmacother. 56 (2002) 296-301.

[9] G. Scambia, F.O. Ranelletti, P. Benedetti Panici, R. De Vincenzo, G. Bonanno, G. Ferrandina, M. Piantelli, S. Bussa, C. Rumi, M. Cianfriglia, et al., Quercetin potentiates the effect of adriamycin in a multidrug-resistant MCF-7 human breast-cancer cell line: P-glycoprotein as a possible target, Cancer Chemother. Pharmacol. 34 (1994) 459-464.

[10] Y.O. Son, S.H. Kook, K.C. Choi, Y.S. Jang, Y.M. Jeon, J.G. Kim, K.Y. Lee, J. Kim, M.S Chung, G.H. Chung, et al., Quercetin, a bioflavonoid, accelerates TNF-alpha induced growth inhibition and apoptosis in MC3T3-E1 osteoblastic cells, Eur. J. Pharmacol. 529 (2006) 24-32.

[11] M.D. Siegelin, D.E. Reuss, A. Habel, A. Rami, A. von Deimling, Quercetin promotes degradation of survivin and thereby enhances death-receptor-mediated apoptosis in glioma cells, Neuro Oncol. 11 (2009) $122-131$.

[12] W. Chen, X. Wang, J. Zhuang, L. Zhang, Y. Lin, Induction of death receptor 5 and suppression of survivin contribute to sensitization of TRAIL induced cytotoxicity by quercetin in non-small cell lung cancer cells, Carcinogenesis 28 (2007) 2114-2121.

[13] D.W. Boulton, U.K. Walle, T. Walle, Fate of the flavonoids quercetin in human cell lines: chemical instability and metabolism, J. Pharm. Pharmacol. 51 (1999) 353-359.

[14] J.P. Spencer, G.G. Kuhnle, R.J. Williams, C. Rice-Evans, Intracellular metabolism and bioactivity of quercetin and its in vivo metabolites, Biochem. J. 372 (2003) 173-181.

[15] C. Daglioglu, B. Okutucu, Synthesis and characterization of AICAR and DOX conjugated multifunctional nanoparticles as a platform for synergistic inhibition of cancer cell growth, Bioconjug. Chem. 27 (2016) 1098-1111.

[16] C. Daglioglu, B. Okutucu, Therapeutic effects of AICAR and DOX conjugated multifunctional nanoparticles in sensitization and elimination of cancer cells via survivin targeting, Pharm. Res. 34 (2017) 175-184.

[17] A. Shapira, Y.D. Livney, H.J. Broxterman, Y.G. Assaraf, Nanomedicine for targeted cancer therapy: towards the overcoming of drug resistance, Drug Resist. Updat. 14 (2011) 150-163.

[18] Q. Yin, J. Shen, Z. Zhang, H. Yu, Y. Li, Reversal of multidrug resistance by stimuli-responsive drug delivery systems for therapy of tumor, Adv. Drug Deliv. Rev. 65 (2013) 1699-1715.

[19] G. Minotti, P. Menna, E. Salvatorelli, G. Cairo, L. Gianni, Anthracyclines: molecular advances and pharmacologic developments in antitumor activity and cardiotoxicity, Pharmacol. Rev. 56 (2004) 185-229.

[20] W.X. Ren, J. Han, S. Uhm, Y.J. Jang, C. Kang, J.H. Kim, J.S. Kim, Recent development of biotin conjugation in biological imaging, sensing, and target delivery, Chem. Commun. 51 (2015) 10403-10418.

[21] J. Fu, Y. Zhu, Lysosomes activating chain reactions against cancer cells with a pH-switched prodrug/procatalyst co-delivery nanosystem, J. Mater. Chem. B. 5 (2017) 996-1004.

[22] B. Wang, C. Xu, J. Xie, Z. Yang, S. Sun, pH controlled release of chromone from chromone- $\mathrm{Fe}_{3} \mathrm{O}_{4}$ nanoparticles, J. Am. Chem. Soc. 130 (44) (2008) 14436-14437.

[23] S. Laurent, D. Forge, M. Port, A. Roch, C. Robic, L.V. Elst, R.N. Muller, Magnetic iron oxide nanoparticles: synthesis, stabilization, vectorization, physicochemical characterizations, and biological applications, Chem. Rev. 108 (2008) 2064-2110.

[24] N.A. Lapin, Y.J. Chabal, Infrared characterization of biotinylated silicon oxide surfaces, surface stability, and specific attachment of streptavidin, J. Phys. Chem. B 113 (2009) 8776-8783. 
[25] M. Heneczkowski, M. Kopacz, D. Nowak, A. Kuźniar, Infrared spectrum analysis of some flavonoids, Acta. Pol. Pharm. 58 (2001) $415-420$.

[26] S. Simoes, J.N. Moreira, C. Fonseca, N. Düzgüneș, M.C.P. de Lima, On the formulation of $\mathrm{pH}$-sensitive liposomes with long circulation times, Adv. Drug Delivery Rev. 56 (2004) 947-965.
[27] D. Staedler, E. Idrizi, B.H. Kenzaoui, L. Juillerat-Jeanneret, Drug combinations with quercetin: doxorubicin plus quercetin in human breast cancer cells, Cancer Chemother. Pharmacol. 68 (2011) 1161-1172.

[28] H. Kaiserova, T. Simunek, W.J. van der Vijgh, A. Bast, E. Kvasnickova, Flavonoids as protectors against doxorubicin cardiotoxicity: role of iron chelation, antioxidant activity and inhibition of carbonyl reductase, Biochim. Biophys. Acta 1772 (2007) 1065-1074. 